\title{
MODELO DE PARCERIA ICT E EMPRESAS PARA DESENVOLVIMENTO DE INOVAÇÃO TECNOLÓGICA: ESTUDO DE CASO DO IPT EM PROJETO COM FINANCIAMENTO DA EMBRAPII
}

Gabrielle Branco Fabri (gabrielle.fabri@aluno.ufabc.edu.br) - Programa de Pós-Graduação em Engenharia e Inovação - UFABC

Flávia Gutierrez Motta (fgmotta@ipt.br) - Programa de Pós-Graduação em Engenharia e Inovação $\mathrm{UFABC} / \mathrm{IPT}$

\begin{abstract}
RESUMO
Inovação é fator essencial para a competitividade de empresas. Esta tendência tem empurrado as empresas a buscar conhecimentos e informações externas. Desenvolver parceiras em conjunto com ICTs tem sido caminho para empresas que investem em inovação. A Embrapii busca estimular o investimento das empresas em P,D\&I em parceria com ICTs e foco em introduzir inovações no mercado. Esse artigo analisa esse novo contexto nas parcerias entre ICT-empresa. Explorou-se um estudo de caso específico dentro da atuação do IPT no projeto piloto realizada pelo MCTi para testar e modelar a implementação da Embrapii. $O$ objetivo do artigo consistiu em descrever o modelo conceitual de TT no âmbito ICT-Empresa a partir do modelo de eficácia contingente de transferência de tecnologia de Bozeman (2000). A pesquisa pautou-se na questão: "o projeto realizado pela parceria ICT-Empresa cumpre com o objetivo de realizar TT?". O estudo de caso mostrou a eficiência do modelo de Bozeman. A Embrapii se mostrou flexível, não tendo editais pontuais, e as empresas conseguem realizar $P \& D$ dentro da estratégia traçada. Em relação ao impacto no mercado e desenvolvimento econômico, a avaliação dos resultados gerados apresentou limitações visto que o projeto não chegou ao resultado esperado principalmente por causa do prazo determinado.
\end{abstract}

Palavras-chave: Interação universidade-empresa; transferência de tecnologia; parcerias públicoprivadas.

Área: Open Innovation

\section{INTRODUÇÃO}

Até meados do século XX, as empresas aderiam a seguinte filosofia: sucesso em inovação requer controle. Sendo assim, empresas deveriam gerar suas próprias ideias, desenvolvê-las, produzi-las, lançá-las no mercado e distribuí-las (CHESBROUGH, 2003), tudo baseado em recursos internos Por anos essa lógica de inovação dentro das barreiras da empresa foi o "caminho certo" para trazer novas ideias ao mercado.

Enquanto o paradigma dominante inovação até a década de 1990 foi abordagem fechada, durante as últimas duas décadas uma série de fatores começou a serem alinhados para mudar a maneira de inovação das empresas. Para permanecerem nos mercados competitivos as empresas modernas precisam desenvolver produtos inovadores em uma taxa muita mais rápida em comparação com o passado. Ao mesmo tempo, o conhecimento das pessoas fora da firma se tornou mais acessíveis graças ao advento da internet, plataformas de redes sociais, uma cultura de partilha, e da disponibilidade de algoritmos de busca cada vez mais 
sofisticados. Estas tendências empurraram empresas para buscar peritos externos para complementar o conhecimento interno para um grau mais elevado.

Para acelerar o processo de desenvolvimento de inovações, tem surgido a necessidade das empresas de serem capazes de explorar a inovação através de modelos de negócios "abertos", acessando um número de mercados e promover a inovação em colaboração com parceiros. As relações inter organizacionais assumem papel relevante nesse modelo, levando a inovação a ser considerada como resultante de redes distribuídas interorganizacionais, ao invés de firmas isoladas (COOMBS et al., 2003, POWELL et al., 1996). Esse movimento desperta o interesse dos estudos acadêmicos sobre inovação, onde vários conceitos de inovação "interativa" foram apresentados para entender o caráter não-linear, interativo e multiagente dos processos de inovação (KLINE, 1985, LUNDVALL, 1988, VON HIPPEL, 1987).

Um tipo de interação interessante é a ligação entre organismos públicos de pesquisa e as indústrias. As universidades e instituições de ensino têm papel fundamental na P\&D no Brasil e, consequentemente, na inovação. Cherubiri Neto (2006) e Maculan e Merin (1998), apontam que as empresas têm ampliado os recursos externos de $P \& D$ e a importância das universidades como provedoras deste, têm aumentado.

A interação ICT-empresa pode ocorrer de diversas formas, podendo ser desde relações pessoais informais, a convênios formais e criação de estruturas próprias para interação. Os convênios têm objetivos definidos, podendo ocorrer através de pesquisa contratada, desenvolvimento de protótipos e testes, treinamento de funcionários, projetos de pesquisa cooperativa ou programas de pesquisa conjunta. Já na criação de estruturas próprias para a interação, podem-se citar como exemplos, parques tecnológicos, institutos, laboratórios, incubadoras de empresas e consórcios de pesquisa (ENGEROFF et al., 2008).

Este artigo pretende colocar luz sobre o processo de inovação entre os atores de um arranjo de inovação tecnológica ICT-empresa. Além dessa seção introdutória, o trabalho ainda conta mais quatro seções. A seguinte discorre sobre a fundamentação teórica da cooperação de transferência de tecnologia e conhecimento que subsidiam a pesquisa. A seção 3 apresenta a metodologia utilizada, focando, particularmente, no método utilizado para análise do estudo de caso, enquanto a seção 4 discorre sobre os resultados e a ultima seção sobre as conclusões.

\section{FUNDAMENTAÇÃO TEÓRICA}

\subsection{Definição de Inovação}

O termo inovação possui diversas definições. Uma inovação pode ser definida como uma ideia, uma prática ou um bem material que é percebido como novo e de relevante aplicação (ZALTMAN et al, 1973). O termo também envolve a busca, experimentação, descoberta, imitação, desenvolvimento e adoção de novos produtos, novos processos produtivos e novas configurações organizacionais (DOSI, 1988). Por sua própria definição, o conceito supõe e impõe uma relação estreita entre inovação e conhecimento. Nesse trabalho utilizaremos o termo inovação como o processo de produção de conhecimento.

A inovação é gerida dentro de um modelo que apresenta a divisão do processo de inovação em basicamente três fases (CHESBROUGH, 2003): (a) fase de conceito, onde ideias novas e pesquisas são realizadas; (b) fase de desenvolvimento, na qual ideias são transformadas em projetos e (c) fase de negócios/comercialização, na qual projetos são transformados em novos negócios. Cada um dessas fases necessita de uma ação e atividade diferente do gestor do projeto, e o resultado final de um projeto de inovação exige um bom gerenciamento de cada etapa. 
O modo como é gerenciam o processo de inovação nos levam a duas abordagens, a abordagem fechada e a abordagem aberta de inovação. O primeiro, inovação fechada, limita o processo inovador aos conhecimentos, conexões e tecnologias desenvolvidos dentro das organizações, sem participação de instituições externas ou outras empresas no processo. Já o segundo, inovação aberta, considera como parte do processo inovador também o conhecimento e tecnologias externos aos da organização com objetivo inovador e sugere o envolvimento de universidades, outras organizações parceiras, do mercado através dos consumidores, fornecedores e do canal de distribuição. Nesse sentido, as empresas não precisam confiar apenas na sua capacidade interna, mas pode incluir capital humano e financeiro para gerir o processo de inovação.

O conceito de Inovação aberta, ou Open Innovation, criado pelo economista americano Henry Chesbrough em 2003, traduz as observações de práticas utilizadas por corporações de vários tamanhos desde a década de 60. Por meio da definição dos fundamentos do conceito, companhias de todos os tamanhos podem compartilhar conhecimentos e desenvolver soluções tecnológicas em conjuntos para acelerar sua evolução. Nessa perspectiva, Salunke et al. (2011) destacam o aprendizado e o compartilhamento como fator chave de desenvolvimento e geração de inovações para as empresas.

A inovação aberta abre espaço para um amplo mercado de ideias, um mercado de talentos e um mercado de financiamento, criando um ecossistema que funcione como uma teia colaborativa em que todos consigam encontrar sinergia com outras empresas e profissionais. É importante notar, que muito antes da concepção do termo de inovação aberta, várias empresas já realizavam atividades e práticas que podem ser definidas como parte do modelo proposto por Chesbrough.

O desafio principal do modelo de inovação aberta está no encontro das ferramentas certas para um bom trabalho colaborativo, integrando descobertas cientificas de forma que traga novidade a uma nova experiência de consumo. Podemos dizer que, de modo geral, a capacidade de inovar depende da capacidade das sociedades e das relações entre seus agentes, movimentos, organizações e instituições.

Wang (2012) expõe que o modelo de inovação aberta representa uma ruptura de valores, na qual o conhecimento passa a ser adquirido por meio de parceiros que em conjunto adquirem competências necessárias à inovação em virtude de sua complementaridade. Vale ressaltar esse conceito, pois para uma parceria ser bem sucedida, os atores devem ter de maneira clara a competência de seus parceiros e de como será realizado o projeto de modo, a saber, se isso complementa suas próprias competências.

Assim, de acordo com Dosi (1988), há a necessidade de maior aproximação entre empresas e academia, a fim de melhor agir sob a incerteza, cada vez mais presente no novo contexto competitivo; sob a dependência por renovação tecnológica e de negócio, em que os custos de inovação podem ser reduzidos pelo compartilhamento do conhecimento; sob a crescente formalização das atividades de $\mathrm{P} \& \mathrm{D}$, deixando-as mais flexíveis e passíveis de venda, caso não atendam aquilo que se almejava; e sob o learning-by-doing, aprender fazendo, o que reforça o processo de aprendizagem.

Pode-se entender que o processo de inovação aberta é uma forma de buscar a competitividade, trabalhando em parcerias para alcançar objetivos maiores, dividindo riscos e lucros, além de conseguir agregação econômica até nas ideias que não servem para o propósito da empresa que a gerou. No entanto, apesar das vantagens apresentadas, a concepção de inovação aberta ainda precisa vencer alguns paradigmas. 
O próximo capitulo mostra como o conceito de inovação aberta é estimulado dentro do sistema econômico e quais resultados são gerados.

\subsection{Cooperação entre organizações}

Partindo do princípio de que a inovação é o foco de um mundo em evolução, em que prevalecem complexas relações entre três organizações que têm diferentes funções. Etzkowitz e Leydesdorff (1995) e Etzkowitz (2005) propuseram o modelo da Hélice Tripla (figura 1), no qual as parcerias evoluem com integração entreempresas, universidades e governo que cooperam para apoiar a interface dessas organizações (PORTO et al, 2011). No modelo da triplice hélice, o governo encarrega-se de promover um arranjo institucional propício à interação entre academia e empresas, podendo atuar também como financiador, por meio de suas agências de fomento. A academia garante capacitação e transferência de conhecimento e tecnologia. E a empresa insere-se no arranjo transformando esse conhecimento em produtos e em valor econômico (ABREU et al, 2016).

Figura 1. Modelo de Hélice Tripla. Fonte: Abreu et al (2016)

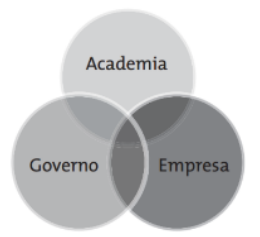

As estruturas de colaboração envolvem vários atores que se coordenam para atingir objetivos por meio da conjugação de suas respectivas competências. Cada uma das formas de colaboração, no âmbito da inovação aberta, constitui um segmento separado de investigação na literatura acadêmica.

Nota-se que o processo de cooperação pode atingir alta complexidade, pois apresenta diversos formatos de arranjos por finalidades e, além disso, pode assumir variações no grau de relações entre as partes. A inovação pode ocorrer em quatro tipos diferentes de estratégias, que podem se misturar e formar diversos arranjos entre empresas seja entre fornecedores ou até mesmo concorrente, ou ainda universidades e centros de pesquisa, com a possibilidade de ampliar a dinâmica e as possibilidades de inovação (BELDERBOS et al, 2006).

Segundo Reis (1998), o relacionamento com universidades é considerado um dos mais efetivos meios de obtenção de inovação tecnológica pelas organizações. As empresas têm a visão de que as universidades podem complementar o seu esforço tecnológico e gerar vantagem competitiva com redução de custo de pesquisa. As empresas sofrem com a restrição de recursos internos suficientes para desenvolver pesquisas isoladamente (PORTO, 2011).

Um dos mecanismos utilizados para o desenvolvimento tecnológico na parceira ICT-empresa é a transferência de tecnologia, tema que é mostrada na próxima seção.

\subsection{Transferência de tecnologia}

Transferência de tecnologia é um mecanismo empregado pela firma para obter recursos tecnológicos necessários para criar inovação a partir de recursos externos, em uma relação de negócio envolvendo dois perfis: o fornecedor e o receptor (SABATER, 2010). Bozeman (2000) assume que a transferência de tecnologia inclui, por definição, vários atores e, em geral, essas partes envolvidas têm metas diversas e múltiplos critérios de eficácia.

A transferência, para o setor produtivo, de tecnologias geradas em centros de pesquisa, universidades, institutos é de fundamental importância dentro de uma estratégia de aumento 
da competitividade das indústrias em busca de novos mercados e da própria sobrevivência no mercado nacional e internacional (RIBEIRO, 2001).

Tratando-se de tecnologias geradas no meio acadêmico, a transferência de tecnologia é definida como um processo que consiste de várias etapas, que inclui a revelação da invenção, o patenteamento, o licenciamento, o uso comercial da tecnologia pelo licenciado e a percepção dos royalties pela universidade (SANTOS et al, 2004).

O modelo tradicional de TT por meio de patentes não é o único canal, nem o mais eficiente, para realizar essa atividade, conforme já identificado pelo estudo da OECD (2013). Muitas tecnologias ou conhecimentos tecnológicos, utilizam outros mecanismos tanto formais quanto informais(Bozeman, 2000; Link, Siegel, \& Bozeman, 2007; Romero, 2007). A transferência de tecnologia no contexto do estudo corresponde a um processo de transferência de conhecimentos e de competências específicas, desenvolvidas a partir da realização de pesquisas, que tem por finalidade promover a capacitação tecnológica das empresas receptoras (MARCHIORI, COLENCI, 1998). De acordo com a Associação Nacional de Entidades Promotoras de Empreendimentos Inovadores (ANPROTEC, 2002) a transferência de tecnologia significa o intercâmbio de conhecimentos e habilidades tecnológicas entre instituições de ensino superior e/ou centros de pesquisa e empresas.

Nesse trabalho analisou a transferência de tecnologia como um processo de construção conjunta de conhecimento e tecnologia entre ICT e empresa à luz do Modelo de Eficácia Contingente de Transferência de Tecnologia de Bozeman (2000), o qual foi elaborado especificamente para tratar das desse tipo de processo. Esse artigo analisa o contexto de geração de conhecimentos tecnológicos e inovação nas parcerias entre ICT-empresa buscando observar os pontos fortes e fracos nesse processo, em especial destacando como os projetos são geridos e os resultados e impactos para os parceiros e para a sociedade como um todo. Para isso irá explorar um estudo de caso específico - a atuação do IPT na ação piloto realizada pelo MCTi para testar e modelar o formato para a implementação da Embrapii.

\section{ARCABOUÇO METODOLÓGICO}

A revisão da literatura permitiu conceber um modelo conceitual para entender o processo de desenvolvimento de parceria envolvendo ICT-empresa. O estudofoi desenhado dentro de uma abordagem qualitativa descritiva, com metodologia de um único estudo de caso, partindo da revisão bibliográfica da obra de Bozeman acerca de paradigmas de avaliação de transferências tecnológicas. Foi adotada uma concepção construtivista social, aquela em que o objetivo é segundo Creswell (2010) confiar o máximo possível nas visões que os participantes têm da situação a qual está sendo estudada. A amostra foi feita por seleção intencional dentro dos diversos projetos geridos dentro o Instituto de Pesquisas Tecnológicas do Estado de São Paulo (IPT) que abordam o tema de nanotecnologia e que foram realizados dentro do projeto piloto da Embrapii.

O projeto escolhido para estudo engloba uma multinacional na área de borrachas e tem desenvolvido conteúdo tecnológico com parcerias com ICTs no Brasil. Para essa pesquisa, foi concebido roteiro de entrevista com assuntos a serem abordados de maneira aberta levando em conta o modelo de avaliação de TT de Bozeman, o roteiro foi um teste que será extendida a aplicação para outros 19 projetos.

\subsection{Esquema do estudo: modelo de Bozeman}

O modelo desenvolvido por Bozeman (2000) denominado modelo contingente de eficácia de transferência de tecnologia (Contingent Effectiveness Technology Transfer Model), assume 
que as partes envolvidas na transferência de tecnologia entre universidade-empresa têm múltiplos objetivos e critérios de eficácia, como mostrado na figura 2. Suas setas indicam as relações entre as dimensões, sendo que as linhas tracejadas representam as ligações mais fracas no processo (BOZEMAN, 2000).

Trata-se de um modelo que faz referencia com os resultados do processo de transferência de tecnologia entre ICT-empresa, e é voltado para a efetividade das ações, como as dimensões que determinam as características da transferência e os critérios qualitativos de eficácia dos resultados da transferência.

Com o modelo de Bozeman (2000) foi possível a descrição do processo de transferência de tecnologia e dos resultados encontrados, contemplando os inputs (entradas), outputs (saídas), os efeitos da transferência e sobretudo objetivando a maior eficácia do processo em uma estrutura de um arranjo de construção coletiva de conhecimento e tecnologia entre um ICT, no caso dessa pesquisa o Instituto de Pesquisas Tecnológicas (IPT) e empresas que realizam projeto com o instituto através do programa piloto da Empresa Brasileira de Pesquisa e Inovação Industrial (EMBRAPII).

Figura 2. Modelo de Bozeman. Fonte: Bozeman (2000)

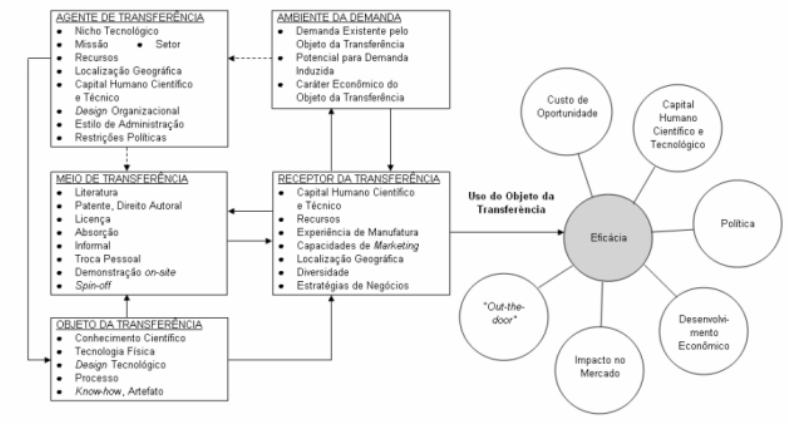

\subsection{Programa piloto da Embrapii}

A Empresa Brasileira de Inovação Industrial (Embrapii) é uma forma de fomento para projetos de PDI em pesquisas aplicadas pré-competitivas entre ICTs e empresas que têm ampliado o incentivo para investimento das empresas em P\&D cuja operação se iniciou em 2012.

Tem como missão principal aumentar os investimentos em inovação das empresas industriais, fomentando projetos conjuntos a serem desenvolvidos entre as ICTs credenciadas e as empresas. Como pressupostos desse modelo, incluem-se três pontos principais, o compartilhamento de gastos (sistema de terços), uma estrutura ágil (fast-track), a simplificação dos processos, entre outros.

É uma estrutura bastante peculiar e nova no cenário de inovação do país. Apresenta um modelo bastante diverso daquele em operação pelas agências de fomento tradicionais, nos quais as Instituições (como BNDES, Finep e FAP's) lançam editais e avaliam o projeto para decidir se a pesquisa será apoiada. No caso da Embrapii a avaliação do projeto é realizada pela Instituição de Ciência e Tecnologia (ICT), sendo necessário que a ICT cumpra com diversos requisitos de capacitação técnica e de gestão para ser credenciada e poder atuar com esse fomento (EMBRAPII, 2014).

Esse modelo antes de iniciar sua operação definitiva, que ocorreu em 2014, passou por uma fase de teste piloto. Nessa etapa três ICTs participaram do processo de teste do modelo: o Instituto Nacional de Tecnologia (INT), o Senai/CIMATEC, e o Instituto de Pesquisa Tecnologia (IPT). A duração do piloto foi de 24 meses para o processo de contratação de 
pesquisas e de 48 meses até finalizar todos os projetos contratados e foi disponibilizado pelo governo federal R\$30 milhões para cada instituição participante. Conforme a regra de financiamento estabelecido em que cada participante do projeto aplicava um terço dos recursos necessários para o desenvolvimento, isso significou um montante total de $R \$ 90$ milhões em projetos financiados pela Embrapii, pelas empresas contratantes e pelas três ICTs.

\subsection{Instituto de pesquisas tecnológicas do Estado de São Paulo (IPT)}

O IPT é um instituto público de pesquisa, vinculado à Secretaria do Desenvolvimento Econômico, Ciência e Tecnologia do Estado de São Paulo, e atua como Unidade Embrapii nas áreas de desenvolvimento de tecnologias de materiais e desenvolvimento e escalonamento de processos biotecnológicos, temas nos quais possui tradição de pesquisa, capacitação e infraestrutura diferenciada, fatores fundamentais para ser credenciado pela Embrapii.

O instituto participou da etapa piloto com credenciamento para atuação nas áreas de Biotecnologia, Nanotecnologia, Microtecnologia e Novos Materiais Metálicos, Poliméricos e Cerâmicos.

\section{RESULTADOS}

O IPT desenvolveu 20 projetos na etapa piloto do projeto Embrapii. Este estudo avaliou apenas um projeto e é a base para ajuste e adequações na forma de realizar avaliação de transferência de tecnologia. Foi escolhido um projeto para fazer um estudo de caso preliminar, mas a intenção é estender esse estudo para todos os projetos desenvolvidos na área de nanotecnologia do instituto.

\subsection{Dimensões do modelo de eficácia contingente}

Observando os itens levantados por BOZEMAN (2000) foi levantada a gestão e estrutura da transferência de tecnologia entre uma empresa e o IPT dentro do projeto piloto Embrapii.

A demanda do projeto surgiu a partir de reuniões entre a empresa e IPT. O tema levantado durante esses encontros estava vinculado ao plano estratégico da empresa que visa segurança e integridade do processo de envelhecimento da borracha. O projeto faz parte de demandas de pesquisa e desenvolvimento da empresa na área de matérias, englobando também a área de projetos. O IPT já possuía know-how no encapsulamento de nanopartículas, mas não tinha empregado esse conhecimento dentro da borracha, sendo assim o instituto ajustou o curso de uma pesquisa diante de uma oportunidade de aplicação que se apresentou.

Segundo a empresa, o material utilizado na fabricação dos pneus não era conhecido pela área de nanotecnologia do instituto, sendo assim, durante as etapas do projeto a empresa disponibilizou seu know-how ao instituto para criação conjunta de conhecimento. A interação entre o fornecedor e a instituição receptora da tecnologia permitiu ao fornecedor conhecer de maneira plena as necessidades do receptor e por outro possibilitou a capacitação necessária para que este alcançasse o domínio da tecnologia. Isso confirma a suposição de que uma interação com o receptor da tecnologia é essencial para a transferência do conhecimento tecnológico e assim os objetivos finais resultam de fato na tecnologia desenvolvida com proposito para a empresa. Outro ponto importante, é que as pessoas que participaram do projeto continuam na empresa e podem difundir o conhecimento adquirido.

O agente da inovação (fornecedor) se caracteriza pela área de bionanomanufatura no IPT que tenho como missão viabilizar o desenvolvimento e aplicação de nanotecnologias de forma integrada e sustentável, respondendo às demandas de mercado. O instituto conta com seu próprio modelo de negocio para gerir os projetos. O método de transferência foi gerido 
totalmente pelo instituto, e a empresa se adaptou, assim como faz para cada parceiro de pesquisa. Como o projeto não chegou ao resultado final desejado, a transferência ocorreu como uma troca de conhecimento entre os envolvidos.

Como o projeto tinha tempo limitante de 24 meses ele foi finalizado sem o resultado esperado pela empresa. A cápsula se rompia quando em contato com a borracha principalmente pelo fator dinâmico de material.

\subsection{Critérios de eficácia da transferência de tecnologia}

Como o projeto não chegou ao seu resultado esperado não é observado impacto no mercado e desenvolvimento econômico. Mesmo assim, a empresa se mostrou positiva com os avanços da pesquisa e cumprimentos de prazos. Até o momento não tem retornos econômicos, financeiros ou políticos, mas está negociando com o instituto a segunda fase do projeto.

\section{CONSIDERAÇÕES FINAIS}

Para responder o problema de pesquisa proposto neste trabalho, foi identificado, através de análise de caso único, os critérios de eficácia de acordo com o Modelo de Eficácia Contingente de Transferência de Tecnologia de Bozeman (2000). O modelo mostrou-se adequado para analisar o caso, embora não tenho uma amostra comparativa.

O modelo Embrapii se mostra mais flexível quanto a diversos temas de pesquisa, não ficando preso a editais pontuais, e mostra que as empresas conseguem realizar P\&D dentro da estratégia traçada, onde o ambiente da demanda da tecnologia pode ser caracterizado por um mix entre as necessidades de mercado identificadas pelo receptor de tecnologia ou por aquelas apresentadas pelos agentes da transferência a partir de suas pesquisas. Como o acordo de cooperação se dá apenas entre o instituto e a empresa as relações fluem mais fáceis, mas vale lembrar que as pessoas envolvidas no processo podem modificar essa visão.

Em relação ao impacto no mercado e desenvolvimento econômico, a avaliação dos resultados gerados pelas transferências de tecnologia apresentou limitações, pois o projeto não chegou ao resultado esperado principalmente por causa do prazo delimitado. Mesmo com todos os enclaves gerados a empresa se mostrou satisfeita e planeja um novo projeto junto ao instituto para continuação dos estudos.

\section{REFERÊNCIAS}

ABREU, I. et al. Parques tecnológicos: panorama brasileiro e o desafio de seu financiamento. BNDS, Revista do BNDES, p. 99-154, 2016.

ANPROTEC, Associação Nacional de Entidades Promotoras de Empreendimentos de Tecnologias Avançadas, \& SEBRAE. Glossário dinâmico de termos na área de Tecnópolis, Parques Tecnológicos e Incubadoras de Empresas, 1-124, 2002.

BELDERBOS R, CARREE M, LOKSHIN B. Complementarity in R\&D cooperation strategies. Review of Industrial Organization, 2006.

BOZEMAN, B., Technology transfer and public policy: a review of research and theory. Research Policy. 29. 627-655, 2000.

CHERUBI NETO, R. As Práticas e Ferramentas da Gestão do Conhecimento Auxiliam na Gestão da Interação Universidade-Empresa? Fundamentando e Apresentando a Hipótese. Encontro Nacional de Pós-Graduação em Administração - ANPAD, Salvador, BA, 2006. 
CHESBROUGH, H. W. "Open Innovation: the new imperative for creating and profiting from technology”. Boston, MA: Harvard Business School Press, 2003.

CRESWELL, J. W. Projeto de pesquisa: métodos qualitativo, quantitativo e misto. 2. ed. Porto Alegre: Bookman, 2010

COOMBS, R., HARVEY, M. and TETHER, B. S. Analysing distributed processes of provision and innovation. Industrial \& Corporate Change, 12(6), 1125-1155, 2003.

dos REIS, D. R. Gestão da inovação tecnológica. Manole, 2004.

DOSI, G. Sources, procedures and microeconomic effects of innovation. Journal of Economic Literature, 26(3), 11201171, 1988.

ENGEROFF, R.; BALESTRIN, A. Inovação fechada versus inovação aberta: um estudo decaso da indústria de cutelaria. In: Simpósio de gestão da inovação tecnológica, XXV, Brasília, p. 1-16., 2008.

ETZKOWITZ, H., LEYDESDORFF, L.. The Triple Helix: University - Industry Government Relations: A Laboratory for Knowledge-Based Economic Development. EASST Review 14, 14 - 19, 1995.

ETZKOWITZ, H. Reconstrução criativa: hélice tripla e inovação regional. Rio de Janeiro: Inteligência Empresarial/CRIE/COPPE/UFRJ, n. 23, 2005.

POWELL, W. W., KOPUT, K. W. and SMITH-DOERR, L. Interorganizational collaboration and the locus of innovation: Networks of learning in biotechnology. Administrative Science Quarterly, 41(1), 116, 1996.

PORTO, G. S., et al. Rede de interações universidade-empresa no Brasil: uma análise de redes sociais. Revista de Economia 37.4, 2011.

KLINE, S. J. Innovation is not a linear process. Research Management, 28(4), 36-45, 1985.

LINK, A. N., SIEGEL, D. S., BOZEMAN, B. An empirical analysis of the propensity of academics to engage in informal university technology transfer. Industrial and Corporate Change, 16(4), 641-655, 2007.

LUNDVALL, B.- $\AA$. Innovation as an interactive process: From user-producer interaction to the national system of innovation. In G. Dosi, C. F., G. Silverberg and L. Soete (ed.), Technical change and economic theory. London/New York: Pinter Publishers, 1988.

MACULAN, A.-M.; MERINO, J. C. A. Como avaliar a transferência do conhecimento na interação universidade-empresa. Simpósio de Gestão da inovação Tecnológica. São Paulo, 1998.

MARCHIORI, M. P.; COLENCI Jr, A. Transferência de tecnologia Universidade- Empresa A busca por mecanismos de integração efetiva. XVIII Encontro Nacional de Engenharia de Produção, 1998.

RIBEIRO, P. V. V. Inovação tecnológica e transferência de tecnologia. Brasília, DF, 2001.

ROMERO, F. University-Industry Relations and Technological Convergence. PICMET '07 2007 Portland International Conference on Management of Engineering \& Technology, 233240, 2007.

SABATER J, “Manual de trasferencia de tecnología y conocimiento,” pp. 1- 124, 2010. 
SALUNKE S, Weerawardena J, McColl-Kennedy JR. Towards a model of dynamic capabilities in innovation-based competitive strategy: Insights from project-oriented service firms. Industrial Marketing Management. 2011.

SANTOS, M. E.; SOLLEIRO, J. L., \& LAHORGUE, M. A. Boas Práticas de Gestão em Escritórios de Transferência de Tecnologia. IN: SIMPÓSIO DE GESTÃO DA INOVAÇÃO TECNOLÓGICA, Curitiba, PR, 2004.

von HIPPEL, E. The sources of innovation. New York: Oxford University Press, 1987.

WANG, M. Exploring potential R\&D collaborators with complementary technologies: The case of biosensors. Technological Forecasting \& Social Change, 2012.

ZALTMAN, G.; DUNCAN, R.; HOLBEK, J. Innovations and organizations. John Wiley \& Sons, 1973 